\title{
A Salicylic Acid-Induced Lectin-Like Protein Plays a Positive Role in the Effector-Triggered Immunity Response of Arabidopsis thaliana to Pseudomonas syringae Avr-Rpm1
}

\author{
Grace Armijo, ${ }^{1}$ Paula Salinas, ${ }^{1}$ Mariela Inés Monteoliva, ${ }^{2}$ Aldo Seguel, ${ }^{1}$ Consuelo García, ${ }^{1}$ \\ Eva Villarroel-Candia, ${ }^{1}$ Wei Song, ${ }^{3}$ Alexander Ronald van der Krol, ${ }^{3}$ María Elena Álvarez, ${ }^{2}$ and \\ Loreto Holuigue ${ }^{1}$
}

1Departamento de Genética Molecular y Microbiología, Facultad de Ciencias Biológicas, Pontificia Universidad Católica de Chile, Santiago, Chile; ${ }^{2}$ CIQUIBIC-CONICET; Departamento de Química Biológica, Facultad de Ciencias Químicas, Universidad Nacional de Córdoba, Córdoba, Argentina; ${ }^{3}$ Laboratory of Plant Physiology, Wageningen UR, The Netherlands

Submitted 8 February 2013. Accepted 22 August 2013.

\begin{abstract}
Salicylic acid (SA) is one of the key hormones that orchestrate the pathogen-induced immune response in plants. This response is often characterized by the activation of a local hypersensitive reaction involving programmed cell death, which constrains proliferation of biotrophic pathogens. Here, we report the identification and functional characterization of an SA-induced legume lectin-like protein 1 (SAILLP1), which is coded by a gene that belongs to the group of early SA-activated Arabidopsis genes. SAI-LLP1 expression is induced upon inoculation with avirulent strains of Pseudomonas syringae pv. tomato via an SA-dependent mechanism. Constitutive expression of $S A I-L L P 1$ restrains proliferation of $P$. syringae pv. tomato Avr-Rpm1 and triggers more cell death in inoculated leaves. Cellular and biochemical evidence indicates that SAI-LLP1 is a glycoprotein located primarily at the apoplastic side of the plasma membrane. This work indicates that SAI-LLP1 is involved in resistance to $P$. syringae pv. tomato Avr-Rpm1 in Arabidopsis, as a component of the SA-mediated defense processes associated with the effector-triggered immunity response.
\end{abstract}

Plants have developed sophisticated mechanisms to resist the attack of potentially pathogenic microorganisms. The first line of defense is the recognition of molecular signatures that are common to different classes of microbes (named microbe- or pathogen-associated molecular patterns [PAMPs]) (Bittel and Robatzek 2007). This recognition is mediated by pattern recognition receptors located at the plasma membrane and results in PAMP-triggered immunity (PTI), which prevents proliferation of most potentially pathogenic microorganisms (Monaghan and Zipfel 2012). A second line of defense is the effector-triggered immunity (ETI), activated by effectors named avirulence factors, that pathogens deliver into the plant cell. The avirulence factors are then specifically recognized by intracellular nucleotide-bind-

Corresponding author: L. Holuigue; E-mail: 1holuigue@bio.puc.cl

* The $\boldsymbol{e}$-Xtra logo stands for "electronic extra" and indicates that seven supplementary figures and one supplementary table are published online and that Figures 2 and 3 appear in color online.

(C) 2013 The American Phytopathological Society ing leucine-rich repeat (NB-LRR) disease resistance proteins (Jones and Dangl 2006). The ETI response limits pathogen proliferation at the site of invasion and is often accompanied by the hypersensitive response (HR), characterized by the activation of a programmed cell death (Coll et al. 2011; van Doorn et al. 2011). In addition to the localized HR, a systemic defense response called systemic acquired resistance (SAR) is established in the entire plant after pathogen recognition (Durrant and Dong 2004; Fu and Dong 2013). SAR involves the activation of defense genes, such as those coding for pathogenesis-related (PR) proteins, in distal tissues of the plant to induce a long-lasting and effective defense against a broad spectrum of pathogens (Durrant and Dong 2004; Fu and Dong 2013). Nevertheless, some pathogens that inject virulence effectors into the plant cell are able to evade or suppress PTI and ETI defenses. These pathogens can proliferate in the plant tissues, causing disease or effector-triggered susceptibility (ETS) (Jones and Dangl 2006; Nishimura and Dangl 2010).

The phytohormone salicylic acid (SA) plays a key role in ETI and SAR signaling (Pieterse et al. 2009; Vlot et al. 2009). Tissue levels of SA and its glycosylated conjugates increase locally and systemically after pathogen infection (Fu and Dong 2013; Summermatter et al. 1995). Exogenous application of SA or its structural analogues induces resistance to pathogens (Cao et al. 1994; Ward et al. 1991). On the other hand, SA degradation (in transgenic plants expressing the bacterial salicylate hydroxylase gene $N a h G$ ) or deficiency in its biosynthesis (in plants bearing mutations in the ICS1 gene coding for isochorismate synthase 1) severely reduced ETI and SAR responses (Gaffney et al. 1993; Nawrath and Metraux 1999; Wildermuth et al. 2001).

The role of SA in defense reactions seems to be mainly due to its ability to activate the expression of genes that play important roles in defense (Vlot et al. 2009). Transcriptional regulation of most of the SA-responsive genes is mediated by the master NPR1 co-activator (Dong 2004). Recently, its paralogs NPR3 and NPR4 were identified as receptors of SA that regulate degradation of NPR1, therefore controlling the $\mathrm{SA}$-induced responses mediated by this co-activator ( $\mathrm{Fu}$ and Dong 2013). Although knowledge of SA signaling has advanced in recent years, many essential components for SA action in the cellular response to stress are still unknown ( Fu and Dong 2013; Loake and Grant 2007; Vlot et al. 2009). 
In a previous study, we analyzed the early genetic responses to SA in wild-type (WT) and nprl-1 Arabidopsis seedlings. We found 217 early SA-induced genes, a subset of which was also induced by the avirulent bacterial strain Pseudomonas syringae pv. tomato DC3000 Avr-Rpm1 (Avr-Rpm1) (Blanco et al. 2009). Among the genes of this subset, an NPR1-dependent gene (At5g03350) coding for a putative lectin-like protein of unknown function showed the highest level of induction in response to SA treatment. We named this the SA-induced legume lectin-like protein 1 (SAI-LLPI) gene.

Lectins represent a superfamily of ubiquitous proteins that contain at least one noncatalytic carbohydrate binding domain, also named lectin domain, which allows reversible and specific binding to carbohydrates in polysaccharides, glycoproteins, or glycolipids (Peumans and Van Damme 1995; Sharon and Lis 2002). The plant lectin superfamily includes proteins harboring diverse carbohydrate-binding domains. Due to the high structural and functional diversity of plant lectins, there is still no general consensus to classify them (Jiang et al. 2010; Van Damme et al. 2008; Vandenborre et al. 2011).

Lectins from different families have been connected to plant defense responses. Some jacalin-like lectins were characterized as components of the SA- and jasmonic-acid-mediated defense signaling pathways (Xiang et al. 2011). Additionally, a number of lectins that carry a chitin-binding domain have antifungal properties (Broekaert et al. 1989; Cox et al. 2006; Ramonell et al. 2005). Furthermore, in Arabidopsis, some members of the lectin receptor kinase family (LecRK), which includes kinase proteins containing a legume lectin domain, are transcriptionally induced by pathogens (Bouwmeester and Govers 2009) or elicitor treatments (Riou 2002; Singh et al. 2012). A role in PTI response has been reported for only a small number of these proteins (Arnaud et al. 2012; Bouwmeester et al. 2011; Desclos-Theveniau et al. 2012). In summary, only a few lectins with a function in plant-pathogen interactions have been reported in Arabidopsis.

With the aim of identifying new components of the plant immune system controlled by SA, we here assess the function of SAI-LLP1 in the defense response triggered by Avr-Rpm1 in Arabidopsis thaliana. We report that SAI-LLP1 gene expression is transiently induced by avirulent strains of $P$. syringae pv. tomato via an SA-mediated pathway. Interestingly, constitutive expression of $S A I-L L P 1$ constrains the proliferation of Avr-Rpm1 and increases cell death in the infected tissues. Furthermore, we show evidence indicating that most SAI-LLP1 is found as a glycoprotein tightly bound to the apoplastic side of the plasma membrane. These results implicate SAI-LLP1 in a membrane-associated mechanism induced by SA that is involved in cell death and bacterial growth inhibition processes in the ETI response induced by Avr-Rpm1 in Arabidopsis.

\section{RESULTS}

\section{SAI-LLPI codes for a member}

\section{of the legume lectin-like protein family in Arabidopsis.}

As mentioned above, due to the high diversity of structural features shown by protein members of the plant lectin superfamily, a unique consensus to classify them has not been reached. One of the classifications, based on a comparative analysis of Glycine max, Oryza sativa, and A. thaliana genomes (Jiang et al. 2010), groups lectins from these species into 12 families. In this study, 199 proteins with a lectin domain were reported in Arabidopsis; however, SAI-LLP1 was not included among them.

We performed a search for all the protein sequences containing a carbohydrate-binding domain in the database of The Arabidopsis Information Resource (TAIR). We then curated these sequences manually, selecting the proteins containing a putative lectin domain (defined as a lectin domain by InterPro). We compared our selection with the lists of Arabidopsis proteins containing lectin domains previously reported by Bouwmeester and Govers (2009) and Jiang and associates (2010), and we incorporated the proteins that we had not detected in our search.

We found 226 proteins with a putative lectin domain, most of which have not been yet characterized (Supplementary Table $\mathrm{S} 1)$. By sequence homology analysis, SAI-LLP1 is predicted to belong to the family of legume lectin-like proteins that harbor a legume lectin domain (IPR001220). In Arabidopsis, we found 55 proteins with this domain, and 45 of them belong to the LecRK receptor kinase family (Bouwmeester and Govers 2009). SAI-LLP1 belongs to the group of 10 legume lectin-like proteins that lack a kinase domain and display a putative legume lectin domain as their only distinctive feature (Supplementary Fig. S1A). Among this group, SAI-LLP1 shows the highest similarity with lectins encoded by the genes At3g16530 (65\%) and At3g15356 (60\%). These proteins homologous to SAILLP1 have been associated with the PTI defense response induced by chitin, a fungal PAMP (Lyou et al. 2009; Ramonell et al. 2005), while SAI-LLP1 does not seem to be induced by either chitin or the bacterial PAMP flagellin (flg22 peptide) (Felix et al. 1999), according to our analysis of the GeneVestigator database (Hruz et al. 2008). In contrast to SAI-LLP1, the expression of At3g16530 and At3g15356 (Blanco et al. 2009) is not induced by SA treatment (both genes in the GeneVestigator database) (Hruz et al. 2008).

In the SAI-LLP1 sequence, we found the four conserved loops of legume lectins described by Varki and associates (2009). Because several legume lectin-like proteins from different plant species have been crystallized, we compared the SAI-LLP1 sequence with related proteins, in order to evaluate the presence of conserved amino acids in each loop. The most similar protein (31\% sequence identity) was 3IPVC, a legume lectin protein of Spatholobus parviflorus that specifically binds galactose (Geethanandan et al. 2011). We found that the four loops involved in sugar recognition and binding were the most conserved sequences of SAI-LLP1, supporting the idea that this protein could behave as a lectin.

\section{SAI-LLP1 is induced by avirulent strains} of $P$. syringae via an $\mathrm{SA}$-dependent mechanism.

The $S A I-L L P 1$ expression profile was analyzed by quantitative reverse-transcription polymerase chain reaction (qRTPCR) in 15-day-old WT Arabidopsis seedlings treated for different periods of time with SA. SAI-LLPl induction was detected $2.5 \mathrm{~h}$ after SA treatment and its expression decreased thereafter (Fig. 1A, black bars). In contrast, the expression of $P R-1$, a late SA-induced gene, was maximal $24 \mathrm{~h}$ after SA treatment (Fig. 1A, hatched bars). These results confirm our previous finding that SAI-LLPI is a gene induced early by SA (Blanco et al. 2009).

We also evaluated the basal levels of SAI-LLP1 expression in different developmental stages and tissues. Basal expression of SAI-LLPI is mainly detected in seedlings and leaves of adult plants, and is considerably lower that the expression levels found in seedlings after treatment with SA (Supplementary Fig. S2).

We then evaluated whether the expression of $S A I-L L P 1$ is associated with a particular response against pathogens. For this, SAI-LLPI expression was assessed in 4-week-old WT Arabidopsis plants inoculated with different Pseudomonas strains: P. syringae pv. phaseolicola, for which Arabidopsis is a nonhost plant and induces PTI (Fig. 1B); P. syringae pv. tomato DC3000, a virulent bacterial strain that causes disease 
(Fig. 1C); and DC3000 avirulent strains Avr-Rpm1, Avr-Rpt2, and Avr-Rps4 that induce ETI (Fig. 1D to F). Arabidopsis Col0 ecotype harbors the NB-LRR disease resistance proteins RPM1, RPS2, and RPS4 that recognize the three avirulent effectors Avr-Rpm1, Avr-Rpt2, and Avr-Rps4, respectively.

We observed that SAI-LLP1 expression was only induced upon inoculation with avirulent bacteria, suggesting that its expression and function could be relevant for the ETI response (Fig. 1B to F). In fact, SAI-LLP1 expression was strongly induced in leaves of WT plants inoculated with Avr-Rpm1, AvrRpt2, and Avr-Rps4 between 5 and 8 h postinoculation (hpi). The induction reached levels of 60-, 40-, and 15-fold over basal levels, respectively (Fig. 1D to F, black bars). The bacterial strains analyzed behaved as expected in terms of growth in inoculated leaves of Arabidopsis Col-0 plants (Supplementary
Fig. S3). Similar assays were also performed in sid2-2 plants, which are impaired in SA biosynthesis (Wildermuth et al. 2001). In these plants, the induction of SAI-LLPI expression triggered by inoculation with avirulent bacteria was abolished (Fig. 1D to F, white bars). Collectively, these data indicate that $S A I-L L P 1$ expression is strongly induced during the ETI response triggered by Avr-Rpm 1 and Avr-Rpt 2 effectors and, to a lesser extent, by Avr-Rps4, via an SA-mediated mechanism.

Constitutive expression of $S A I-L L P 1$ potentiates a local defense response against $P$. syringae pv. tomato Avr-Rpm1.

The potential relevance of SAI-LLPI in the Arabidopsis ETI response is suggested by the strong induction of its expression by SA and by avirulent $P$. syringae pv. tomato strains (Fig. 1). In order to address the functional role of SAI-LLP1 in the de-
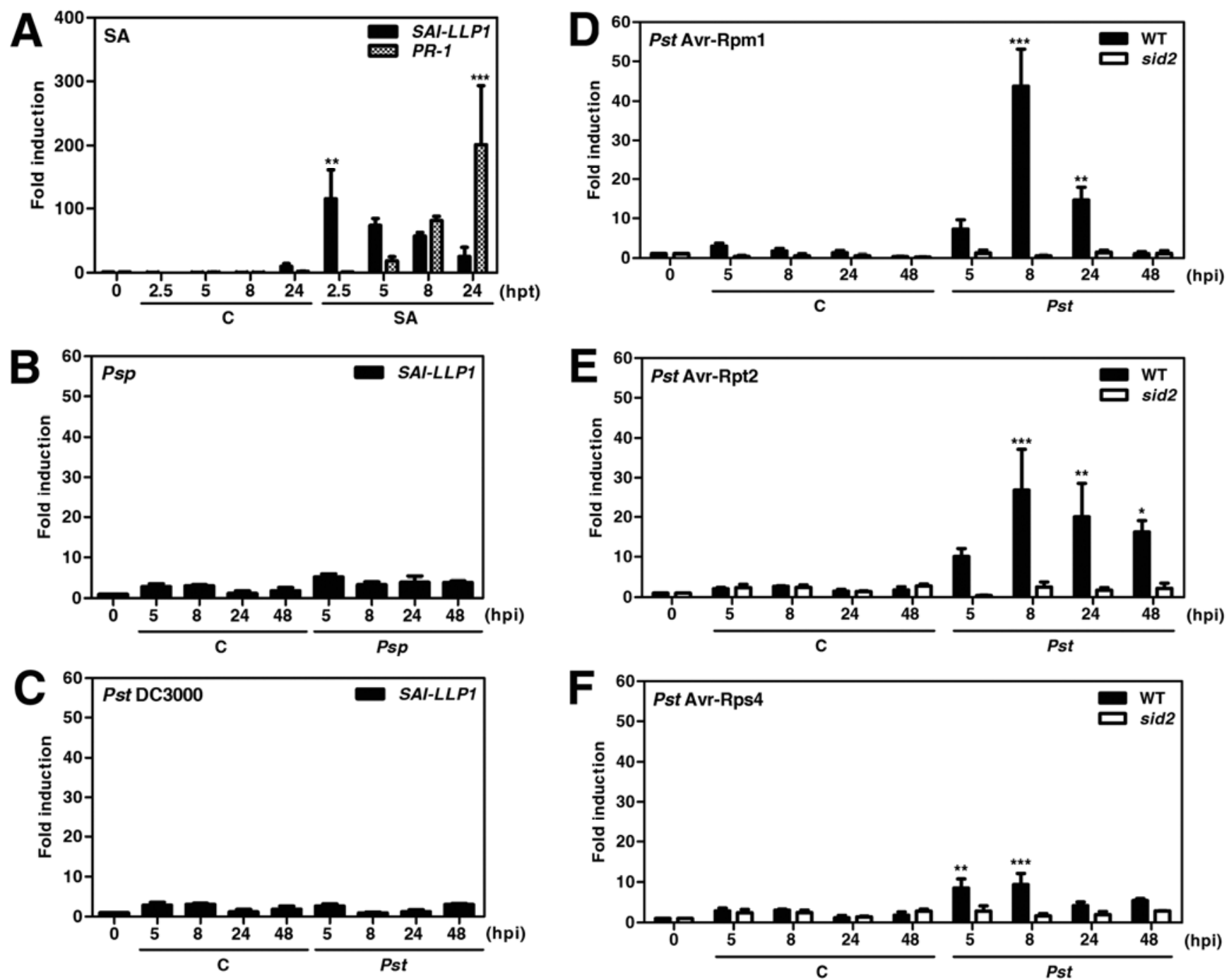

Fig. 1. SAI-LLP1 expression is induced by salicylic acid (SA) and by avirulent strains of Pseudomonas syringae pv. tomato via an SA-dependent pathway. A, Expression profile of SAI-LLP1 after SA treatment. Fifteen-day-old Arabidopsis seedlings were treated with $0.5 \mathrm{mM}$ SA (SA) or Murashige and Skoog medium (MS/2) as a control (C). Samples were collected 0, 2.5, 5, 8, and $24 \mathrm{~h}$ posttreatment (hpt) and the transcript levels of the SAI-LLP1 (black bars) and PR1 (hatched bars) genes were determined by quantitative reverse-transcription polymerase chain reaction (qRT-PCR). B to F, Expression profiles of $S A I-L L P I$ after inoculation with different Pseudomonas strains. Four-week-old wild-type (WT) Arabidopsis plants were inoculated with B, P. syringae pv. phaseolicola; C, P. syringae pv. tomato (DC3000); D, P. syringae pv. tomato DC3000 Avr-Rpm1 (Avr-Rpm1); E, P. syringae pv. tomato DC3000 Avr-Rpt2 (Avr$\mathrm{Rpt} 2$ ); or F, $P$. syringae pv. tomato DC3000 Avr-Rps4 (Avr-Rps4) at $1 \times 10^{6} \mathrm{CFU} / \mathrm{ml}$; or $\mathrm{MgCl}_{2}$ as a control (black bars). For inoculation with avirulent $P$. syringae pv. tomato strains (D to F), sid2-2 plants were also evaluated (white bars). Samples from inoculated leaves were collected $0,5,8,24$, and $48 \mathrm{~h}$ postinoculation (hpi) and the SAI-LLP1 transcript levels were determined by qRT-PCR. Fold induction was calculated by normalizing SAI-LLP1 expression levels to that of the AT4g24550 gene, which codes for a Clathrin adaptor complex subunit, and to the corresponding control condition (T0). Error bars represent standard errors from three biological replicates. For statistical analysis we used a two-way analysis of variance test. Asterisks indicate statistical significant differences A, between $S A I-L L P 1$ and $P R-1$ expression levels or $\mathbf{D}$ to $\mathbf{F}$, between $S A I-L L P 1$ expression levels in WT and sid2-2 plants (*, **, and *** indicate $P<0.05,0.01$, and 0.001 , respectively). 
fense response, we characterized two homozygous insertional mutant lines, sai-llp1-1 and sai-llp1-2, obtained from the Salk Arabidopsis T-DNA bank (Supplementary Fig. S4). T-DNA insertion in both lines resulted in the loss of induction of $S A I$ -
$L L P 1$ expression after SA treatment (Fig. 2A). Together with these mutants, lines expressing the $35 S:: S A I-L L P 1-c-M y c$ construct were obtained. We selected and characterized two homozygous lines (OX-3 and OX-4) that show high basal SAI-LLPI
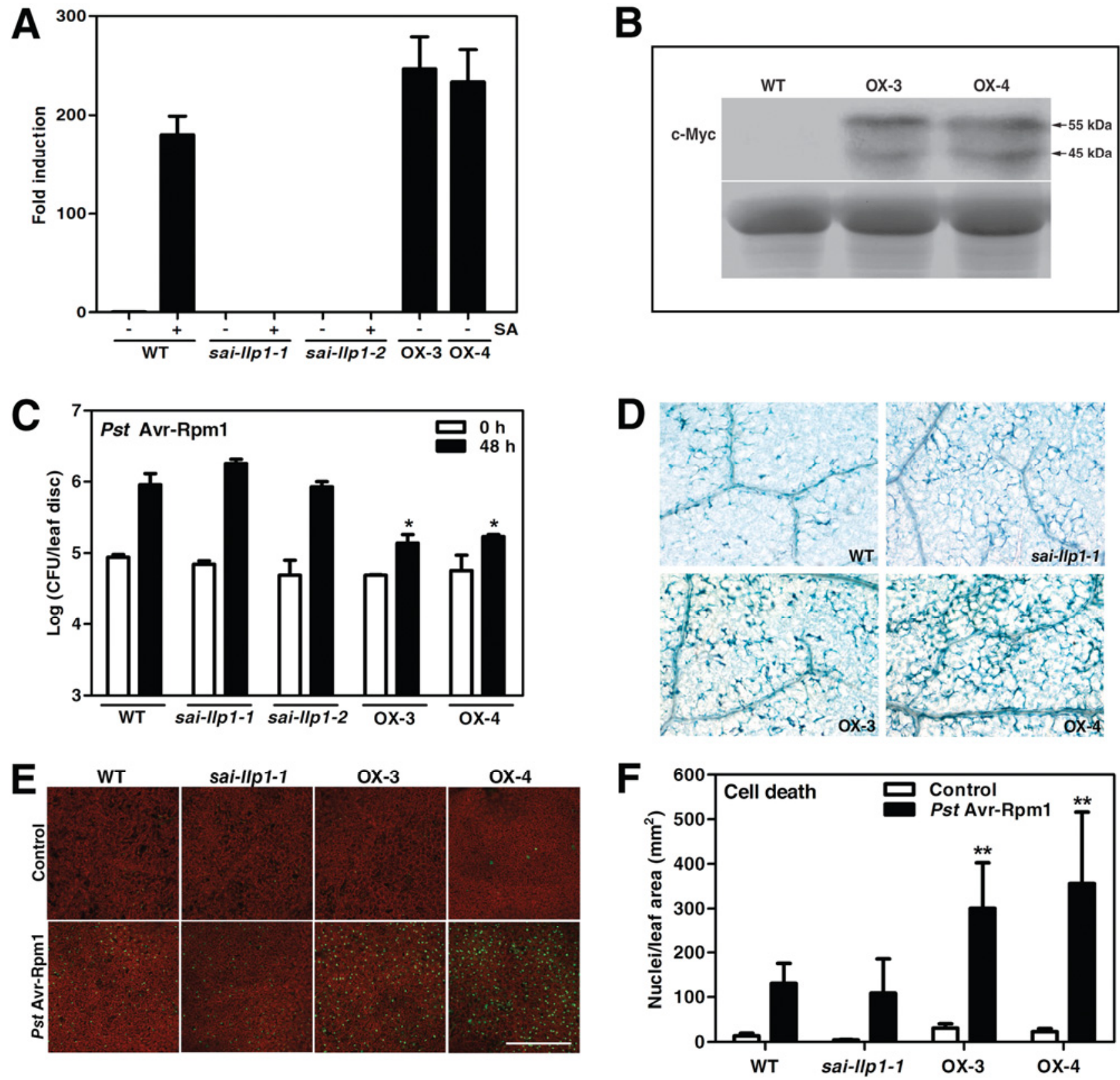

Fig. 2. SAI-LLP1 overexpression potentiates the local defense response to Pseudomonas syringae pv. tomato DC3000 Avr-Rpm1. A, Genetic tools used for the functional characterization of SAI-LLP1. Levels of SAI-LLP1 expression in the wild type (WT), the insertional mutant lines sai-llp1-1 and sai-llp1-2, and the 35S::SAI-LLP1-c-Myc overexpressor transgenic lines (OX-3 and OX-4) were detected by quantitative reverse-transcription polymerase chain reaction analysis. WT and sai-llp1 mutant plants were incubated with $0.5 \mathrm{mM}$ salicylic acid (SA) (+) or with Murashige and Skoog medium (MS/2) (-) as a control for $2.5 \mathrm{~h}$. Overexpressor lines were analyzed without treatment. Fold induction was calculated by normalizing SAI-LLP1 expression to that of the Clathrin adaptor complex subunit gene (AT4g24550) and to the corresponding control condition (WT without treatment). Error bars represent the standard error from three biological replicates. B, Immunoblot analysis of 35S::SAI-LLP1-c-Myc overexpressor lines. The SAI-LLP1-c-Myc protein was detected in OX-3 and OX-4 lines using a c-Myc antibody. WT plants were used as the negative control. The Coomassie blue staining of the protein gel is shown as a loading control. C, Bacterial proliferation assays. Four-week-old WT plants, sai-llp1-1, sai-llp1-2, and the 35S::SAI-LLP1-c-Myc overexpressor transgenic lines (OX-3 and OX-4) were inoculated with Avr-Rpm1 at $1 \times 10^{6} \mathrm{CFU} / \mathrm{ml}$. Leaf discs were taken 0 and $48 \mathrm{~h}$ post infiltration (hpi) and analyzed for bacterial growth quantification (CFU/leaf disc). Each data point represents the average of four technical replicates; error bars indicate standard errors. Statistical analysis was performed using the analysis of variance test; asterisks indicate statistical significant differences with WT plants $(*, P<0.05)$. The graph shows a representative result out of five independent experiments. D to F, Cell death assays. D, Cell death was assessed in leaf tissues of WT, sai-llp1-1, OX-3, and OX-4 lines 48 hpi with Avr-Rpm1, using trypan blue staining. Samples were analyzed by microscopy ( $\times 100$ magnification). E, SYTOX green staining and laser-scanning confocal microscopy was used to monitor cell death levels in Avr-Rpm1-treated leaf tissues 24 hpi. Mock samples inoculated with 10 mM $\mathrm{MgCl}_{2} 24$ hpi were used as controls. Nuclei from dying cells (green) were detected over the background of chlorophyll auto-fluorescence (red). Scale bar $=$ $500 \mu \mathrm{m} . \mathbf{F}$, Quantification of the dying cells in the samples described in $\mathrm{C}$ was performed using the ImageJ software. Values represent the mean and standard deviation of 12 images from three independent experiments. Statistical analysis was performed using a $t$ test; asterisks indicate statistical significant differences with WT plants $(* *, P<0.01)$. 
expression levels, comparable with those found in WT plants treated with SA (Fig. 2A). All these lines showed no obvious phenotypic or morphological differences when compared with WT plants. The SAI-LLP1 protein was detected in the overexpressor lines by immunoblot using the c-Myc antibody (Fig. 2B). Interestingly, in both OX lines, we detected SAI-LLP1-cMyc as two bands with estimated molecular weight of 55 and $45 \mathrm{kDa}$, whereas the expected molecular weight for SAILLP1-c-Myc protein is 38 or $40 \mathrm{kDa}$, depending on whether or not the putative N-terminal signal peptide is processed (Fig. 2B). This double-band pattern of SAI-LLP1-c-Myc suggests that two forms of the protein are produced, which can be due to differential post-translational modifications (Fig. 2B), as will be analyzed and discussed later.

Bacterial proliferation assays were performed in leaves of WT, sai-llp1-1, sai-llp1-2, OX-3, and OX-4 plants inoculated with $P$. syringae pv. phaseolicola, DC3000, and the avirulent Avr-Rpm1, Avr-Rpt2, and Avr-Rps4 strains (Fig. 2C). Only after inoculation with the avirulent Avr-Rpm1 strain did we detect approximately $10 \times$ lower bacterial proliferation in the leaves of both OX lines, compared with the WT and mutant lines (Fig. 2C). This difference was detected 48 hpi and was reproducible for both OX lines in at least five independent experiments.

Because we only detected significant differences in Avr-Rpm1 proliferation, we further characterized the effect of SAI-LLP1 in the response induced by this bacterial strain, evaluating cell death traits as a consequence of HR development. To this end, we analyzed Avr-Rpm1-induced cell death by trypan blue staining in the leaves of WT, mutant and overexpressor SAI-LLPI plants. We found a higher number of dead cells 48 hpi in leaves of overexpressor plants compared with WT and mutant plants (Fig. 2D). We evaluated whether these differences are seen at earlier infection times by staining nuclei of dead cells with SYTOX Green and examining the tissue using confocal microscopy. We quantified the number of dead cells in the inoculated tissues in vivo by counting the number of fluorescent nuclei per leaf area 24 hpi (Truernit and Haseloff 2008). At this time point, cell death was also higher in the tissues of overexpressor lines challenged with Avr-Rpm1 (Fig. 2E and F).

Together, these data indicate that constitutive expression of the $S A I-L L P 1$ gene restricts bacterial proliferation and triggers more cell death in the leaves inoculated with Avr-Rpm1.

\section{SAI-LLP1 is a glycoprotein mainly located at the plasma membrane.}

Bioinformatics analysis to predict the subcellular localization of SAI-LLP1, performed with the Aramemnon database, suggests that SAI-LLP1 is a protein synthesized in the endoplasmic reticulum (ER) and located in a compartment of the protein secretory pathway. Accordingly, a putative cleavable signal peptide sequence was identified in the N-terminal region of the protein, which also has an unobtrusive probability to be a transmembrane-spanning domain (TMD) predicted by Aramemnon. Regarding post-translational modification sequences, we found only two predicted $\mathrm{N}$-glycosylation sites, at N79 and N129 of the SAI-LLP1 protein, using the PROSITE database (Sigrist et al. 2010).

In order to determine the subcellular localization of SAILLP1, we obtained transgenic plants carrying the $35 S:: S A I-$ LLP1-GFP construct and examined them using confocal microscopy (Fig. 3). The SAI-LLP1-green fluorescent protein (GFP) fusion protein was located at the periphery of the cell (Fig. 3A, left panel). Interestingly, we observed a heterogeneous localization where, in some areas, the fusion protein appears to accumulate in patches. In order to establish whether the SAI-LLP1-GFP fusion protein localizes in the plasma membrane or in the cell wall, we subjected the plants to hypertonic treatment with $0.4 \mathrm{M}$ sucrose solution. In plasmolyzed leaf epidermal cells, the SAI-LLP1-GFP protein follows the shrinking pattern of the plasma membrane (Fig. 3A, middle and right panels). In order to confirm this result, we used FM4-64 and propidium iodide (PI) dyes which stain the plasma membrane and the cell wall, respectively. The SAI-LLP1-GFP fusion protein co-localized with FM4-64 (Fig. 3B) but not with PI staining (Fig. 3C), strongly suggesting that SAI-LLP1 is located in the plasma membrane.

We performed biochemical assays to verify the association of SAI-LLP1 with the plasma membrane and its possible glycosylation. For this purpose, total protein extracts obtained from the OX-4 line were fractionated into soluble and microsomal fractions (MF). The MF were treated with Triton X-114 detergent to separate integral or strongly membrane-attached proteins, which remain in the detergent-insoluble fraction, from the soluble or weakly membrane-associated proteins that are found in the detergent solubilized fraction (Wang and Coppel 2002). Using immunoblot analysis, SAI-LLP1 was mainly detected in the MF. Interestingly, the soluble pool of SAI-LLP1c-Myc only contains the isoform of lower estimated molecular mass, while both isoforms are detected in the membrane-associated pool (Fig. 4A; Supplementary Fig. S6). After Triton X114 treatment, SAI-LLP1 was found in the detergent-insoluble fraction (P). This result supports the idea that SAI-LLP1 is strongly associated with the plasma membrane. Nevertheless, a very small fraction of the protein was also detected in the soluble fraction, suggesting the existence of more than one subcellular pool of SAI-LLP1 (Fig. 4A). As a control, we used RIN4, a protein that is strongly attached to the plasma membrane by palmitoylation (Takemoto and Jones 2005). As expected, this protein was only found in the detergent-insoluble fraction $(\mathrm{P})$ (Fig. 4A). To further evaluate the association between SAILLP1 and the plasma membrane, we treated the MF with 0.1 $\mathrm{M} \mathrm{NaCl}$ (to increase the ionic strength) and with $0.1 \mathrm{M}$ $\mathrm{Na}_{2} \mathrm{CO}_{3}$ (to increase the $\mathrm{pH}$ ). After $\mathrm{NaCl}$ treatment, the protein was only detected in the membrane fraction; however, after $\mathrm{Na}_{2} \mathrm{CO}_{3}$ treatment, we also observed a minor proportion of the protein in the soluble fraction. Together, these results indicate that a major proportion of SAI-LLP1 is strongly associated with the plasma membrane, while a minor amount seems to be in a soluble fraction.

To evaluate whether SAI-LLP1 is a glycosylated protein, total extracts from the OX-4 line were treated using an enzymatic deglycosylation kit. After deglycosylation treatment, both bands corresponding to the SAI-LLP1-c-Myc protein shifted to a lower molecular weight (Fig. 4B, lanes 1 and 2), with the lowest band reaching the expected molecular weight of the nonglycosylated form of SAI-LLP1-c-Myc (approximately $40 \mathrm{KDa}$ ). Considering that $S A I-L L P 1$ gene expression is strongly induced in response to Avr-Rpm1 inoculation (Fig. 1D), we evaluated whether this response also affects the post-translational modification of the protein. Our results indicate that the pattern of SAI-LLP1-c-Myc isoforms, before and after deglycosylation treatment, is not altered with Avr-Rpm1 7 hpi (Fig. 4B, lanes 3 and 4) or 48 hpi (data not shown). This evidence supports the idea that both SAI-LLP1 isoforms detected in OX-4 plants are glycosylated and that this modification is not altered during the establishment of the ETI response, at least under the conditions used in the assays.

To further inquire whether $\mathrm{N}$-glycosylation of SAI-LLP1 occurs in the two predicted sites N79 and N129, we searched for evidence of SAI-LLP1 glycopeptides using a general glycoproteomics assay. For this purpose, glycopeptides were isolated from seedlings and leaf tissues of adult plants, subjected to cleavage of the $\mathrm{N}$-glycan moiety by $\mathrm{N}$-glycosidase $\mathrm{F}$ enzyme (PNGaseF), and the resulting peptides were analyzed by liquid 
chromatography-mass spectrometry (LC-MS), as described below (W. Song and A. R. van der Krol, unpublished results).

Five SAI-LLP1-related glycopeptides were detected, all covering the N129 position and each of them having a deamidation at N129 (Table 1). This indicates that SAI-LLP1 is glycosylated at this position. Because $\mathrm{N}$-glycosylation takes place in the luminal side of the ER, our results also indicate that this part of the protein must be facing the ER lumen and, when translocated to the plasma membrane, would face the apoplastic side of this structure.
Together, these results indicate that SAI-LLP1 is an N-glycosylated protein tightly bound to the apoplastic side of the plasma membrane.

\section{DISCUSSION}

In this study, we identified and characterized SAI-LLP1, a member of the legume lectin-like protein family from Arabidopsis that is involved in SA-mediated resistance against AvrRpm1. Collectively, our results show that the SAI-LLP1 gene
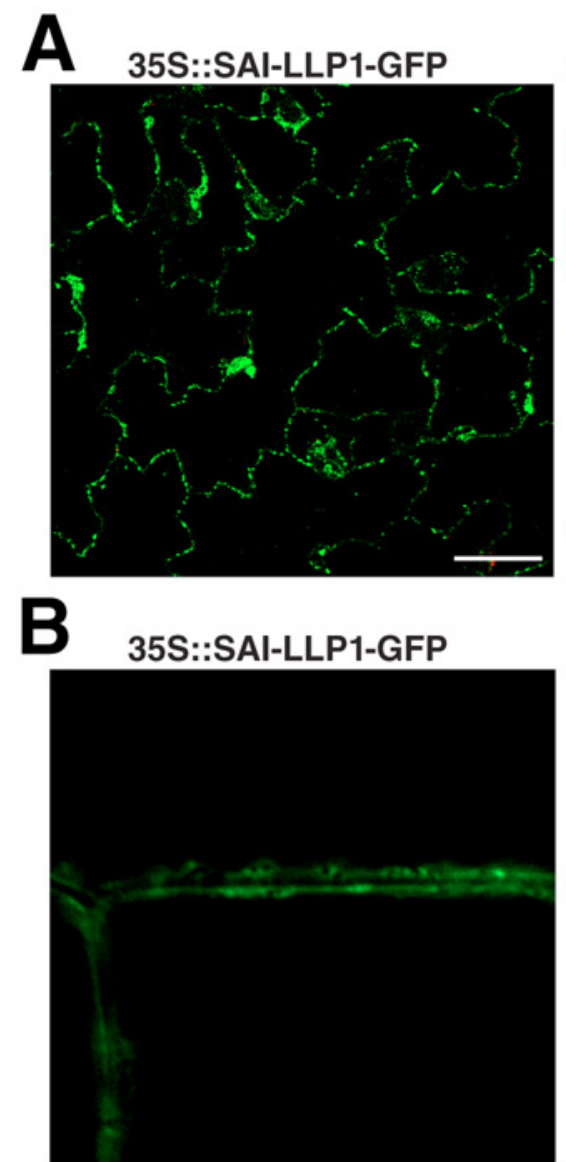

C

35S::SAI-LLP1-GFP

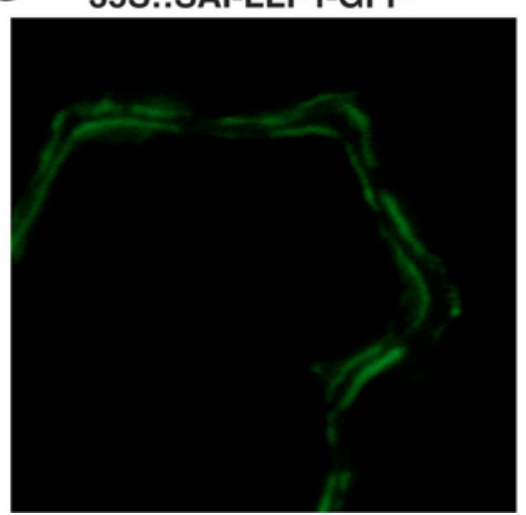

35S::SAI-LLP1-GFP + sucrose

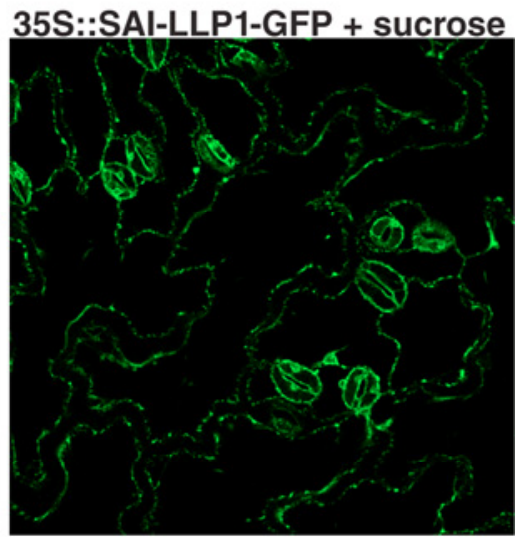

35S::SAI-LLP1-GFP + FM4-64

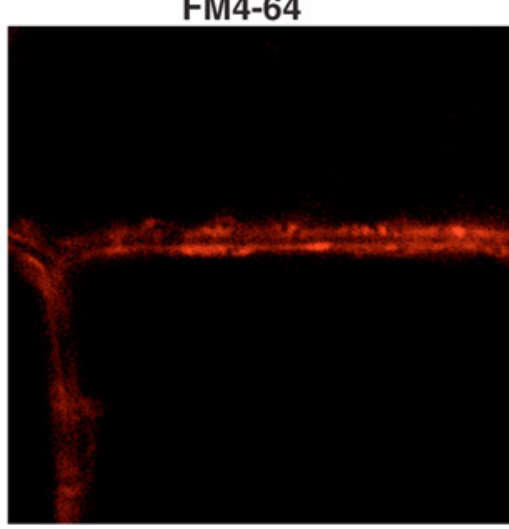

PI

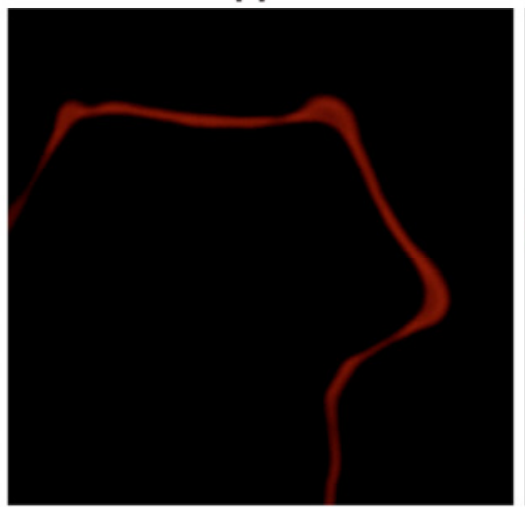

35S::SAI-LLP1-GFP + PI

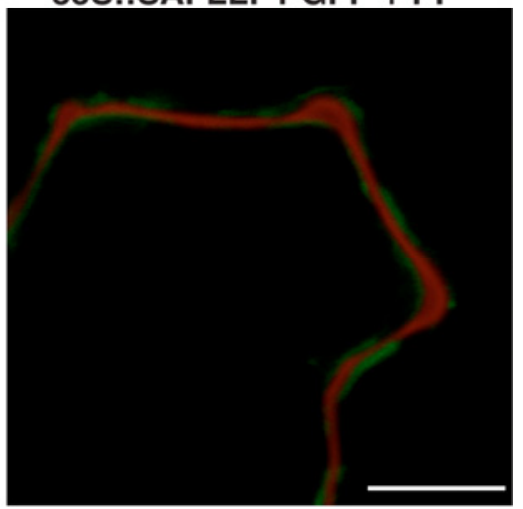

Fig. 3. SAI-LLP1 is localized to the plasma membrane. A, Localization of the SAI-LLP1-green fluorescent protein (GFP) fusion protein after osmotic shock. Leaf epidermal cells from 35S::SAI-LLP1-GFP transgenic Arabidopsis were plasmolyzed by incubation with $0.4 \mathrm{M}$ sucrose for 5 min and immediately examined under the confocal microscope. Left panel shows SAI-LLP1-GFP (green) at T0; middle and right panels are two images in the z-axis taken from the same field after $5 \mathrm{~min}$ of treatment. B and C, SAI-LLP1-GFP co-localizes with a plasma membrane marker. B, For plasma membrane staining, 35S::SAILLP1-GFP roots were incubated in $10 \mu \mathrm{M}$ FM4-64 for $15 \mathrm{~min}$, rinsed with distilled water, and observed immediately. Left panel, SAI-LLP1-GFP (green); middle panel, FM4-64 (red); right panel, merge of the two images. C, For cell wall staining, 35S::SAI-LLP1-GFP seedlings were submerged in a 1:10 dilution of propidium iodide (PI) at $1 \mathrm{mg} / \mathrm{ml}$ and leaf epidermal cells were directly analyzed by confocal microscopy. Left panel, SAI-LLP1-GFP (green); middle panel, PI (red); right panel, merged images. The scale bar represents $10 \mu \mathrm{m}$. 
is strongly and transiently induced by SA treatment and by inoculation with avirulent strains of $P$. syringae pv. tomato via an SA-dependent mechanism. SAI-LLP1 codes for a glycoprotein associated with the apoplastic side of the plasma membrane, and its constitutive expression inhibits bacterial proliferation and triggers an increment in cell death in Avr-Rpm1inoculated tissues. This study indicates that SAI-LLP1 is a component of the SA-mediated defense processes associated with the ETI response.

The expression of SAI-LLPl is strongly and transiently induced, reaching its peak $8 \mathrm{hpi}$, in leaves of Arabidopsis plants inoculated with the avirulent strains Avr-Rpm1 and Avr-Rpt2, and, to a lesser extent, with Avr-Rps4 (Fig. 1D to F). There was no induction in the sid2-2 mutant plants impaired in SA biosynthesis, supporting the idea that SAI-LLP1 expression induced by these bacteria is controlled via an SA-mediated pathway. Inoculation of plant leaves with DC3000 that produces disease, or with $P$. syringae pv. phaseolicola that triggers PTI,

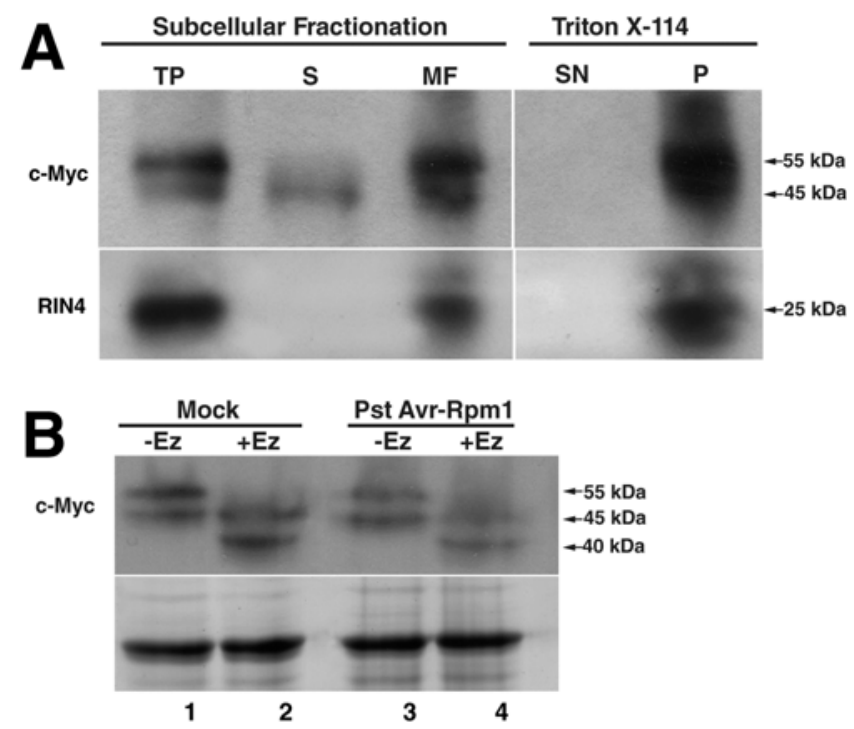

Fig. 4. SAI-LLP1 is a glycosylated protein strongly bound to the plasma membrane. A, Determination of SAI-LLP1 association with the plasma membrane. Soluble (S) and microsomal (MF) fractions were obtained by subcellular fractionation of total protein (TP) extracts of 35S::SAI-LLP1$c-M y c$ OX-4 plants. Fractions enriched in peripheral (supernatant, $\mathrm{SN}$ ) and integral (pellet, $\mathrm{P}$ ) proteins were obtained from the microsomal fraction, following treatment with Triton X-114. SAI-LLP1-c-Myc was detected. RIN4 was detected using the RIN4 antibody and used as control for a plasma membrane-associated protein. B, Enzymatic deglycosylation assays of SAI-LLP1 under control and bacterial-inoculated conditions. Leaves from 35S::SAI-LLPI-c-Myc OX-4 plants were mock (lanes 1 and 2) or Avr-Rpm1 (lanes 3 and 4) inoculated. After $7 \mathrm{~h}$, inoculated leaf samples were collected, total protein extracts obtained, and deglycosylation assays performed using an enzymatic deglycosylation kit. Protein extracts were incubated at $37^{\circ} \mathrm{C}$ for $3 \mathrm{~h}$ with $(+\mathrm{Ez})$ or without $(-\mathrm{Ez})$ the deglycosylation enzymatic mix. The SAI-LLP1-c-Myc protein was detected as described above. Coomassie staining of the protein gel is shown as a loading control. did not induce SAI-LLP1 expression (Fig. 1B and C), suggesting a potential role of this gene in the ETI response triggered by avirulent strains of Pseudomonas.

Involvement of SAI-LLP1 in the ETI response was made evident by constitutive expression of the SAI-LLPl gene, which transiently restricts bacterial proliferation and triggers more cell death in leaves inoculated with Avr-Rpm1 compared with saillp1 mutants and WT plants (Fig. 2). Both, restriction of bacterial growth and cell death are consequences of the ETI response triggered by AvrRpm1 (Alvarez 2000; Pieterse et al. 2009), implicating SAI-LLP1 in SA-mediated processes occurring in the ETI response. Although it was previously thought that cell death accompanying HR is responsible for pathogen growth inhibition, a recent study analyzing the phenotype of mutant plants in the metacaspase 1 gene $(a t m c 1)$ indicates that inhibition of pathogen growth and cell death can be uncoupled processes (Coll et al. 2010). The mechanism by which SAI-LLP1 is involved in these two processes is still unknown.

One of the intriguing aspects from our results is that we did not obtain the same results in inoculations performed with Avr-Rpt 2 compared with those made with Avr-Rpm1, although SAI-LLPI activation was similar in both cases (Fig. 1D and E). A possible explanation for this effect is that SAI-LLP1 is involved in a process that is specific for the RPM1-mediated defense pathway. In this context, it has been shown that defense responses triggered by Avr-Rpm1-RPM1 and Avr-Rpt2RPS2 recognition differ in the induction of autophagy, one of the mechanisms involved in HR cell death. This process is induced by Avr-Rpm 1 but not the Avr-Rpt 2 strain (Hofius et al. 2009). To test this hypothesis, we evaluated whether SAI-LLP1 was involved in autophagy triggered by Avr-Rpm1. However, we did not observe any differences between the overexpressor and WT plants, indicating that SAI-LLP1 is not involved in the autophagy process (Supplementary Fig. S7). We cannot rule out that SAI-LLP1 may participate in another process that is specific for the RPM1-mediated defense pathway. Moreover, we also cannot exclude the idea that this protein may be part of a general mechanism of the ETI response, which cannot be detected in the rest of the $P$. syringae pv. tomato avirulent strains. In fact, we speculate that the effect of SAI-LLP1 overexpression is only detected upon Avr-Rpm1 inoculation due to the robustness of the defense response triggered by this strain. It is well known that Avr-Rpm1 is able to produce a faster and stronger HR compared with other avirulent strains (Mackey et al. 2003; Malinovsky et al. 2010). Furthermore, the low avirulence of Avr-Rpt 2 and Avr-Rps 4 strains detected in our assays (Supplementary Fig. S5) could also explain why a phenotype is noticed only in response to Avr-Rpm1. Although we cannot exclude the possibility that SAI-LLP1 may directly affect AvrRpm1 proliferation, the fact that the genetic background of Avr-Rpm1 and DC3000 (whose proliferation is not affected by SAI-LLP1 overexpression) are the same, except for the AvrRpm1 gene, makes this alternative improbable.

The effect of constitutive expression of SAI-LLP1 on AvrRpm1 bacterial growth was observed only after bacteria infil-

Table 1. Glycosylation site occupancy for salicylic acid-induced legume lectin-like protein 1 (SAI-LLP1), obtained from glycoproteomic analysis

\begin{tabular}{lll}
\hline Accession & \multicolumn{1}{c}{ Sequence $^{\mathbf{a}}$} & Modification $^{\mathbf{b}}$ \\
\hline At5g03350 & IKPAPGHGLAFVVVPSIESDGPGPAGYLGIFNK & Deamidation + N(32) \\
& LGIFNK & Deamidation + N(5) \\
& PAGYLGIFUKTNNGNPK & Deamidation + N $(9)$ \\
& PSIESDGPGPAGYLGIFNK & Deamidation + N $(18)$ \\
& SDGPGPAGYLGIFUKTNNGNPK & Deamidation + N $(14)$ \\
\hline
\end{tabular}

\footnotetext{
${ }^{\text {a }}$ Identified SAI-LLP1 peptide sequences.

${ }^{\mathrm{b}}$ Deamidation of $\mathrm{N}$ to D, due to the action of the N-glycosidase F enzyme that cleaves the N-glycan moiety, was identified in the indicated positions of SAILLP1 peptides.
} 
tration but not after spray inoculation (data not shown). Therefore, we can infer than SAI-LLP1 is not involved in the entry of the bacteria into the intercellular space, as was established for other plasma membrane proteins involved in stomatal aperture and bacterial entry, such as AHA1, AHA2, and LecRKV.5. These proteins conferred higher levels of resistance to plants inoculated by spray than by infiltration (Arnaud et al. 2012; Desclos-Theveniau et al. 2012; Liu et al. 2009).

At the molecular level, we did not detect any differences between WT, mutant, and overexpressor lines regarding the expression levels of classical defense marker genes such as PRI and $W R K Y 70$, a late and an early SA-responsive gene, respectively (data not shown). These lines of evidence indicate that SAI-LLP1 function would be placed in the ETI response triggered after pathogen recognition, downstream of SA production, in a molecular process required to potentiate cell death but not to target the activation of the defense genes expression.

We did not observe any robust phenotype in the sai-llpl mutant lines challenged with any of the bacterial strains used, compared with WT plants. The basal expression of genes coding for other legume lectin-like proteins similar to SAI-LLP1 in Arabidopsis raises the possibility of functional redundancy. In fact, SAI-LLP1 is the only legume lectin-like protein without a kinase domain that is coded by a gene induced by SA, other proteins from this family, such as those coded by At3g15356, At3g16530, and At1g53070 genes, were identified in noninoculated tissues as proteins localized in the apoplast or loosely associated with the cell wall (Boudart et al. 2005). Interestingly, according to our results, SAI-LLP1 seems to face the apoplastic space, as will be discussed below (Fig. 4). Therefore, we conclude that SAI-LLP1, although it is involved in the ETI response, is not essential for the development of the response, probably due to functional redundancy with the pool of lectin proteins already present in the apoplastic space under basal conditions.

Biochemical analysis in SAI-LLP1-c-Myc overexpressor plants identifies two N-glycosylated isoforms of the protein, one strongly bound to membranes and one that seems to be soluble (Fig. 4). Whether the soluble isoform of SAI-LLP1 is loosely bound to the membrane or directly secreted to the apoplast, and whether this isoform is generated by cleavage of the putative signal peptide or by differential modification, are possibilities that need to be investigated.

We have not established how SAI-LLP1 is attached to the plasma membrane but some possibilities include binding to the plasma membrane by a noncanonical post-translational modification, through strong interactions to another plasma membrane glycoprotein, or by forming part of a lipid raft or microdomain that is resistant to detergent extraction. Supporting the last alternative, the confocal microscopy analysis in SAI-LLP1GFP overexpressor plants showed that the fusion protein associated with the plasma membrane does not have a homogenous distribution (Fig. 3A). However, we cannot rule out that this pattern is the result of SAI-LLP1-GFP overexpression. Furthermore, although the prediction of a TMD in the N-terminal region of SAI-LLP1 is not robust, it raises the possibility that the protein may be anchored to the plasma membrane through this sequence. Further studies are required to elucidate the nature of SAI-LLP1 interactions with the plasma membrane.

Glycosylation is a common post-translational modification found in legume lectin-like proteins (Ashford et al. 1991). Accordingly, we showed experimental evidence indicating that SAI-LLP1 is an N-glycosylated protein and that N129 is at least one of the residues affected by this modification (Fig. 4B; Table 1). We did not detect peptides with evidence of glycosylation at N79, suggesting that this residue is not glycosylated. Because N-glycosylation occurs at the luminal side of the ER, the N-glycosylated isoforms of SAI-LLP1 must be at the apoplastic side of the plasma membrane or directly in the apoplastic space for the case of the soluble fraction. We think that the N-glycosylation must be essential for the appropriate function of SAI-LLP1 in the plasma membrane. Interestingly, the pattern of SAI-LLP1 glycosylation does not seem to be altered at the onset of the ETI response.

Taking all these results into account, in this work, we report the discovery of a legume lectin-like protein involved in an SA-mediated mechanism of the ETI defense response that potentiates or accelerates the onset of cell death. The mechanism by which SAI-LLP1 exerts this function and whether this is also important for constraining proliferation of other biotrophic pathogens that triggers ETI in Arabidopsis remain to be elucidated. This is the first report of a legume lectin-like protein from Arabidopsis involved in the HR cell death process.

\section{MATERIALS AND METHODS}

\section{Plant lines and growth conditions.}

Plants were grown either on soil or on plates containing Murashige and Skoog (MS)/2 medium (Sigma-Aldrich, St. Louis) with $1 \%$ sucrose and $0.8 \%$ agar (or $0.27 \%$ phytagel agar) (Sigma-Aldrich) under controlled conditions in a growth chamber (16 h of light, $\left.100 \mu \mathrm{mol} \mathrm{m} \mathrm{s}^{-2}, 22 \pm 2^{\circ} \mathrm{C}\right)$. WT plants were Col-0 ecotype. The sid2-2 mutant (in a Col-0 background) was previously described by Wildermuth and associates (2001). The sai-llp1 mutants, also in the Col-0 background, were obtained from the Salk Arabidopsis T-DNA bank. The SALK 036814 (sai-llp1-1) line was genotyped by PCR using the left border T-DNA primer 5'-GCGTGGACCGCTTGCTGCAACT$3^{\prime}$ or the SAI-LLP1 primer 5'-TTGGGAAAATGAAACACTG GTC $-3^{\prime}$ as forward primers and the primer $5^{\prime}$-CATTCCGGT TACAACTTTCTGATAC- $3^{\prime}$ as the reverse primer. Selection of the SALK_133264 (sai-llp1-2) homozygous line was achieved by antibiotic segregation, because it was not possible to amplify the T-DNA insertion by PCR. SAI-LLPl expression in both homozygous mutant lines was null, evaluated by qRTPCR as described below.

\section{Bacterial strains and growth conditions.}

P. syringae pv. phaseolicola NPS3121, P. syringae pv. tomato DC3000 virulent strain, and its isogenic avirulent strains expressing the Avr-Rpm1, Avr-Rpt2 (Mackey et al. 2002), or AvrRps4 (Aarts et al. 1998) effectors were used. Bacterial strains were grown at $28^{\circ} \mathrm{C}$ on King's B medium supplemented with rifampicin at $50 \mu \mathrm{g} / \mathrm{ml}$ (for the $P$. syringae pv. phaseolicola strain) or kanamycin at $50 \mu \mathrm{g} / \mathrm{ml}$ (for the other strains).

\section{Plasmid constructs and plant transformation.}

Arabidopsis lines overexpressing SAI-LLP1 were obtained by Agrobacterium-mediated transformation (Clough and Bent 1998). Constructs were generated using the Gateway cloning system (Invitrogen, Carlsbad, CA, U.S.A.). The SAI-LLP1 coding sequence was amplified by PCR using cDNA from SAtreated Arabidopsis seedlings as the template, and the primers 5'-CCACATGGGGATTCATAAACTCTGTTTTCTTGC-3' and 5'-GATTCTCTTGGCACTGTTCTGGAAGGTCC-3'. The amplified fragment was cloned into the pENTR/SD/D-TOPO vector, then inserted into the destination vectors $\mathrm{pBADcMyc}$ (to overexpress the protein fused to a c-Myc tag) and pK7FWG2 (to overexpress the protein fused to GFP). These constructs were transferred to Agrobacterium tumefaciens (GV3101 strain), and Arabidopsis Col-0 plants were transformed using the floral dip method (Clough and Bent 1998). Homozygous transgenic lines were selected and transgene expression was analyzed by qRT-PCR and Western blot in the 
case of $35 S:: S A I-L L P 1-c-M y c$ lines and by confocal microscopy to the $35 S:: S A I-L L P 1-G F P$ lines.

\section{SA treatment and bacterial inoculation.}

SA treatment was carried out in 15-day-old seedlings grown in $\mathrm{MS} / 2$ medium and placed root side down in liquid MS/2 medium containing $0.5 \mathrm{mM}$ sodium salicylate (Riedel-deHaen, Seelze, Germany), or MS/2 medium alone as a control. Seedlings were collected $0,5,8$, and $24 \mathrm{~h}$ after treatment, immediately frozen in liquid nitrogen, and stored at $-70^{\circ} \mathrm{C}$ until RNA purification.

For bacterial inoculation assays, a suspension of $1 \times 10^{6}$ $\mathrm{CFU} / \mathrm{ml}$ in $10 \mathrm{mM} \mathrm{MgCl}$, was infiltrated on the abaxial side of the leaves of 4-week-old plants, using a needleless syringe. Mock-treated plants were infiltrated with $10 \mathrm{mM} \mathrm{MgCl}_{2}$ alone. For local gene expression analysis, bacteria- and mock-infiltrated leaf samples were collected $0,5,8,24$, and $48 \mathrm{~h}$ postinfiltration, frozen in liquid nitrogen, and stored at $-70^{\circ} \mathrm{C}$ until RNA purification. For proliferation assays, leaf discs were taken $0,24,48$, and $72 \mathrm{~h}$ postinfiltration from 6 independent plants, ground in $10 \mathrm{mM} \mathrm{MgCl}$, serially diluted $1: 10$, and plated onto King's B agar plates with the appropriate antibiotics. Plates were incubated at $28^{\circ} \mathrm{C}$ for 2 days and the number of CFU was counted.

\section{RNA analysis.}

Total RNA was isolated using the Trizol reagent (Invitrogen). For qRT-PCR analysis, samples containing $2.5 \mu \mathrm{g}$ of total RNA were treated with RQ1 DNase (Promega Corp., Madison, WI, U.S.A.) and first-strand cDNA was synthesized using random primers and MML-V Reverse Transcriptase (Promega Corp.), following the manufacturer's instructions. qRT-PCR analysis was performed using an Mx3000P system (Stratagene, Agilent Technologies, Santa Clara, U.S.A.). The primers used for qRT-PCR were SAI-LLP1: 5'-TTTGATCGT

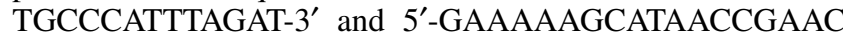
AG-3'; PR-1: 5'-GTGGGTTAGCGAGAAGGCTA-3' and 5'ACTTTGGCACATCCGAGTCT-3'; and Clathrin adaptor complex subunit: 5'-AATACGCGCTGAGTTCCCTT-3' and 5'-AGCACCGGGTTCTAACTCAA-3'. The expression levels of SAI-LLPI and PR-1 were calculated relative to the Clathrin adaptor complex subunit (AT4g24550) housekeeping gene using the $\Delta \Delta \mathrm{Ct}$ method (Livak and Schmittgen 2001).

\section{Confocal microscopy.}

The subcellular localization of SAI-LLP1-GFP was analyzed in 35S::SAI-LLP1-GFP transgenic lines by confocal microscopy. Transgenic seedlings (15 days old) were sampled randomly, mounted in water, and directly analyzed. To distinguish between plasma membrane and cell wall labeling, leaf epidermal cells were plasmolyzed by incubation in a $0.4 \mathrm{M}$ sucrose solution for $5 \mathrm{~min}$ and then examined under the microscope. For FM4-64 and PI staining, 35S::SAI-LLP1-GFP transgenic leaves were submerged in $10 \mu \mathrm{M}$ FM4-64 in water for $15 \mathrm{~min}$ or immersed in a 1:10 dilution of PI $(1 \mathrm{mg} / \mathrm{ml})$ and observed immediately. Samples were observed with an Olympus LSM Fluoview 1000 confocal microscope and image projections were made with the Olympus FV-Viewer Confocal software. For GFP detection, a 488-nm excitation laser was used and fluorescence was collected with a 505- to 530-nm bandpass filter. For FM4-64 or PI staining, 515- and 543-nm excitation lasers were used and fluorescence was collected with a 615-nm low-pass filter.

\section{Protein analysis.}

Total protein extracts were obtained by grinding the tissue in liquid $\mathrm{N}_{2}$ and resuspending it in $1 \mathrm{ml}$ of extraction buffer (50
mM HEPES [pH 7.5], $50 \mathrm{mM} \mathrm{NaCl,} 10 \mathrm{mM}$ EDTA, 0.2\% Triton X-100, and protease and phosphatase inhibitor cocktails) (Invitrogen). Homogenates were then centrifuged at 15,800 $\times g$ for $10 \mathrm{~min}$ at $4^{\circ} \mathrm{C}$ and stored at $-70^{\circ} \mathrm{C}$. Sodium dodecyl sulfate (SDS) polyacrylamide gel electrophoresis and subsequent immunoblotting were performed according to Liu and associates (2011). c-Myc antibody (Invitrogen) was used at a concentration of 1:6000. The RIN4 antibody was generously donated by G. Coaker (Department of Plant Pathology, University of California-Davis, U.S.A.) and used as described by Liu and associates (2011). The secondary rabbit anti-mouse immunoglobulin G-HRP conjugate (Kirkegaard \& Perry Laboratories, Gaithersburg MD, U.S.A.) was used at a concentration of 1:5000, as described above.

\section{Deglycosylation and membrane purification assays.}

To assay the deglycosylation of SAI-LLP1, $25 \mu \mathrm{g}$ of total protein extracts of transgenic OX-4 (35S::SAI-LLP1-c-Myc) plants, mock and Avr-Rpm1 inoculated, were treated with or without the GlycoPro Enzymatic Deglycosylation kit (ProZyme, Inc., San Leandro, CA, U.S.A.), according to the manufacturer's guide. The SAI-LLP1-c-Myc protein was then detected by Western blot as described above, and the presence or absence of glycosylation was determined by changes in protein electrophoretic mobility after enzymatic treatment. For membrane purification assays, $15 \mathrm{~g}$ of 4-week-old leaves was ground in liquid $\mathrm{N}_{2}$ and resuspended in $15 \mathrm{ml}$ of extraction buffer $(50$ $\mathrm{mM}$ Tris [pH 8.0], $100 \mathrm{mM} \mathrm{NaCl}, 20 \mathrm{mM}$ dithiothreitol [DTT], $0.33 \mathrm{M}$ sucrose, and $1 \mathrm{mM}$ phenylmethanesulfonyl fluoride [PMSF]). To obtain the MF, homogenates were filtered with Miracloth (Calbiochem/Merck, Darmstadt, Germany) and centrifuged at $3,000 \times g$ for $20 \mathrm{~min}$ at $4^{\circ} \mathrm{C}$ to eliminate cell debris. Samples were ultracentrifuged at $138,000 \times g$ for $2 \mathrm{~h}$ at $4^{\circ} \mathrm{C}$; the supernatant (soluble fraction, S) was recovered and the pellet (MF) was resuspended in $3 \mathrm{ml}$ of $50 \mathrm{mM}$ phosphate buffer ( $\mathrm{pH} 7.5), 20 \mathrm{mM} \mathrm{NaCl}$, and $1 \mathrm{mM}$ PMSF. Peripheral proteins were isolated using Triton X-114 (Sigma-Aldrich) according to Sedbrook and associates (2002) and Varet and associates (2003). Briefly, the MF were treated with Triton $\mathrm{X}-114$ at a final concentration of $2.4 \%$ for $15 \mathrm{~min}$ at $4{ }^{\circ} \mathrm{C}$, transferred to $37^{\circ} \mathrm{C}$ for $5 \mathrm{~min}$, then centrifuged at $1,000 \times g$ for $20 \mathrm{~min}$. The detergent-solubilized fraction (weakly membraneassociated proteins, $\mathrm{SN}$ ) were recovered and the pellets (detergent-insoluble fraction, integral or strongly membrane-attached proteins) were treated with methanol-chloroform to remove excess detergent. All fractions obtained were analyzed by immunoblotting as described above.

\section{Glycoproteomics analysis.}

Glycopeptide isolation was performed according to Tian and associates (2007), with the indicated modifications. Briefly, frozen Arabidopsis tissues (leaves of 6-week-old plants and whole 2-week-old seedlings) were ground, and proteins were extracted with protein extraction buffer (8 M urea, $0.05 \%$ SDS, $5 \mathrm{mM}$ DTT, $25 \mathrm{mM}$ EDTA, and $0.1 \mathrm{M}$ Tris-HCl, $\mathrm{pH}$ 8.0). The protein extracts were digested with trypsin (Sigma-Aldrich) and glycan moieties from glycopeptides were activated by $\mathrm{NaIO}_{4}$. Activated glycopeptides were coupled to the hydrazide resin beads (Bio-Rad, Munich). Nonglycopeptides were first washed away with dimethylformamide and Mili Q water, then by PNGaseF buffer (50 mM sodium phosphate, $\mathrm{pH} 7.5$ ). Bound glycopeptides were subjected to cleavage of the N-glycan by PNGaseF (peptide N-glycosidase F) (New England Biolabs, Beverly, MA, U.S.A.), which results in the deamidation of the $\mathrm{N}$ residue linked to the glycan to $\mathrm{D}$. Further purifications were applied before LC-MS. Raw LC-MS data were processed for peptide or protein identification by ProteinLynx and Mascot. 
Glycopeptide identification was based on the combined criteria: spectral quality, deamidation ( $\mathrm{N}$ to $\mathrm{D}$ ) in the N-X-S/T glycosylation consensus site, and secretion signal present in the identified proteins (SignalP).

PNGaseF enzyme only cleaves non-complex N-glycans. Then, to allow isolation of the glycopeptides with our technology, the COMPLEX GLYCAN LESS $c g l$ mutants that abolish modifications to complex N-glycans were used (Strasser et al. 2005; von Schaewen et al. 1993).

\section{Cell death analysis.}

Cell death was visualized in adult leaves infiltrated with AvrRpm1 $\left(10^{6} \mathrm{CFU} / \mathrm{ml}\right)$ by trypan blue staining (Pavet et al. 2005) or SYTOX green staining (Molecular Probes/Invitrogen) (Truernit and Haseloff 2008). For trypan blue staining, infected and control leaves were immersed in lactophenol (water, basic phenol, lactic acid, and glycerol in a 1:1:1:1 ratio) containing trypan blue at $250 \mu \mathrm{g} / \mathrm{ml}$ and placed in boiling water for $3 \mathrm{~min}$. Then, leaves were cleared in lactophenol without trypan blue at room temperature for $16 \mathrm{~h}$. For examination, leaves were mounted in $50 \%$ glycerol and observed using a compound microscope at $\times 100$ magnification. For the second assay, leaves were vacuum-infiltrated with SYTOX Green $(0.2 \mu \mathrm{M}, \mathrm{pH} 7.0)$, maintained in the dark for 20 min before washing with water, and analyzed by laser-confocal microscopy (Zeiss LSM5 Pascal) to determine the abundance of dying cells, as described by Cecchini and associates (2011). Images were taken using a $\times 10,0.3$ numerical aperture (UPlanFLN; Olympus, Tokyo) objective and a confocal aperture of $200 \mu \mathrm{m}$. Images of both the dye fluorescence (excitation, $488 \mathrm{~nm}$; emission, 505 to 530 $\mathrm{nm}$ ) and the plant autofluorescence (excitation, 633; emission, $650 \mathrm{~nm}$ ) were acquired for the same field using a sequential acquisition mode. The number of nuclei per leaf area (square millimeters) was quantified using ImageJ software (National Institutes of Health, Bethesda, MD, U.S.A.).

For autophagy determination, LysoTracker Green fluorescence was detected by confocal microscopy, as described above, using the same settings as for GFP fluorescence. Leaves were vacuum-infiltrated with $1 \mathrm{mM}$ LysoTracker 3 and $6 \mathrm{~h}$ after bacterial infection and kept for an additional hour in darkness before visualization. Quantitation of autophagosomallike structures were made according to Hofius and associates (2009).

\section{Bioinformatics analyses.}

To identify proteins with a putative lectin domain in the database of TAIR, we used the "carbohydrate-binding domain" as a selection criterion, and then we curated the sequences manually, taking into consideration all the proteins with InterPro lectin domain. For this selection, we considered the following domains: legume lectin domain (IPR001220), mannosebinding lectin (IPR001229), malectin (IPR021720), calreticulin/calnexin P domain (IPR009033), bulb-type lectin domain (IPR001480), concanavalin A-like lectin/glucanases superfamily (IPR008985), ricin B lectin domain (IPR000772), galectin carbohydrate recognition domain (IPR001079), D-galactoside/ L-rhamnose binding SUEL lectin domain (IPR000922), and C-type lectin (IPR001304). Finally, we contrasted the list of proteins with those reported by Bouwmeester and Govers (2009) and Jiang and associates (2010).

To build the phylogenetic tree, all legume lectin-like proteins from Arabidopsis that lack a kinase domain were considered. Protein sequences obtained from TAIR were grouped by segments and aligned using the multiple alignment program DIALIGN 2 (Morgenstern 1999). For phylogenetic relationships evaluation, the alignments were analyzed by the neighbor joining method using the software MEGA 5.0 (Tamura et al. 2011) and the robustness of the clades was determined with 1,000 bootstrap replicates. The tree was visualized using the same software, and the concanavalin A sequence was used as an external group.

We compared the SAI-LLP1 sequence with that of the other plant legume lectin-like proteins already described and characterized. For this purpose, the primary sequence of legume lectin-like proteins crystallized was obtained from the Protein Data Bank (PDB) and a multiple alignment among these sequences and SAI-LLP1 was performed by using the T-Coffee program (Notredame et al. 2000). The most similar protein to SAI-LLP1 was searched by BLAST using the PDB database protein.

Bioinformatics analysis of the possible subcellular localization of SAI-LLP1 was performed with the Aramemnon database, which uses several programs to predict transmembrane spanning domains, topology of proteins, and subcellular localization. The hydrophobicity profile of SAI-LLP1 was analyzed by using the program SUBA (Heazlewood et al. 2007). To predict possible post-translational modifications of SAI-LLP1, the following programs were used: $\mathrm{N}$-glycosylation sites at PROSITE database (Sigrist et al. 2010), myristoylation at the NMTMYR Predictor and the Plant-Specific Myristoylation Predictor, and glycosylphosphoinositol (GPI) at the GPI Modification Site Prediction.

\section{ACKNOWLEDGMENTS}

This work was supported by the National Commission for Science and Technology CONICYT (FONDECYT grant number 1100656) and the Millennium Science Initiative (Nucleus for Plant Functional Genomics, grant number P10-062-F). G. Armijo was supported by a Ph.D. fellowship from CONICYT. We thank G. Coaker (Department of Plant Pathology, University of California-Davis, U.S.A.) for providing the RIN4 antibody, G. León (Laboratorio de Reproducción y Desarrollo de Plantas, Centro de Biotecnología Vegetal, Universidad Andres Bello, Santiago, Chile) for helping with the analysis of SAI-LLP1-GFP localization using confocal microscopy, and L. Cottet for some of the bioinformatics analyses.

\section{LITERATURE CITED}

Aarts, N., Metz, M., Holub, E., Staskawicz, B. J., Daniels, M. J., and Parker, J. E. 1998. Different requirements for EDS1 and NDR1 by disease resistance genes define at least two $\mathrm{R}$ gene-mediated signaling pathways in Arabidopsis. Proc. Natl. Acad. Sci. U.S.A. 95:10306-10311.

Alvarez, M. E. 2000. Salicylic acid in the machinery of hypersensitive cell death and disease resistance. Plant Mol. Biol. 44:429-442.

Arnaud, D., Desclos-Theveniau, M., and Zimmerli, L. 2012. Disease resistance to Pectobacterium carotovorum is negatively modulated by the Arabidopsis lectin receptor kinase LecRK-V.5. Plant Signal. Behav. 7:1070-1072.

Ashford, D. A., Dwek, R. A., Rademacher, T. W., Lis, H., and Sharon, N. 1991. The glycosylation of glycoprotein lectins. Intra- and inter-genus variation in $\mathrm{N}$-linked oligosaccharide expression. Carbohydr. Res. 213:215-227.

Bittel, P., and Robatzek, S. 2007. Microbe-associated molecular patterns (MAMPs) probe plant immunity. Curr. Opin. Plant Biol. 10:335-341.

Blanco, F., Salinas, P., Cecchini, N. M., Jordana, X., Van Hummelen, P., Alvarez, M. E., and Holuigue, L. 2009. Early genomic responses to salicylic acid in Arabidopsis. Plant Mol. Biol. 70:79-102.

Boudart, G., Jamet, E., Rossignol, M., Lafitte, C., Borderies, G., Jauneau, A., Esquerre-Tugaye, M. T., and Pont-Lezica, R. 2005. Cell wall proteins in apoplastic fluids of Arabidopsis thaliana rosettes: Identification by mass spectrometry and bioinformatics. Proteomics 5:212-221.

Bouwmeester, K., and Govers, F. 2009. Arabidopsis L-type lectin receptor kinases: Phylogeny, classification, and expression profiles. J. Exp. Bot. 60:4383-4396.

Bouwmeester, K., de Sain, M., Weide, R., Gouget, A., Klamer, S., Canut, H., and Govers, F. 2011. The lectin receptor kinase LecRK-I.9 is a novel Phytophthora resistance component and a potential host target for a RXLR effector. PLoS Pathog. 7:e1001327.

Broekaert, W. F., Van Parijs, J., Leyns, F., Joos, H., and Peumans, W. J. 1989. A chitin-binding lectin from stinging nettle rhizomes with antifungal properties. Science 245:1100-1102. 
Cao, H., Bowling, S. A., Gordon, A. S., and Dong, X. 1994. Characterization of an Arabidopsis mutant that is nonresponsive to inducers of systemic acquired resistance. Plant Cell 6:1583-1592.

Cecchini, N. M., Monteoliva, M. I., and Alvarez, M. E. 2011. Proline dehydrogenase contributes to pathogen defense in Arabidopsis. Plant Physiol. 155:1947-1959.

Clough, S. J., and Bent, A. F. 1998. Floral dip: A simplified method for Agrobacterium-mediated transformation of Arabidopsis thaliana. Plant J. 16:735-743.

Coll, N. S., Vercammen, D., Smidler, A., Clover, C., Van Breusegem, F., Dangl, J. L., and Epple, P. 2010. Arabidopsis type I metacaspases control cell death. Science 330:1393-1397.

Coll, N. S., Epple, P., and Dangl, J. L. 2011. Programmed cell death in the plant immune system. Cell Death Differ. 18:1247-1256.

Cox, K. D., Layne, D. R., Scorza, R., and Schnabel, G. 2006. Gastrodia anti-fungal protein from the orchid Gastrodia elata confers disease resistance to root pathogens in transgenic tobacco. Planta 224:13731383.

Desclos-Theveniau, M., Arnaud, D., Huang, T. Y., Lin, G. J., Chen, W. Y., Lin, Y. C., and Zimmerli, L. 2012. The Arabidopsis lectin receptor kinase LecRK-V.5 represses stomatal immunity induced by Pseudomonas syringae pv. tomato DC3000. PLoS Pathog. 8:e1002513.

Dong, X. 2004. NPR1, all things considered. Curr. Opin. Plant Biol. 7:547-552.

Durrant, W. E., and Dong, X. 2004. Systemic acquired resistance. Annu. Rev. Phytopathol. 42:185-209.

Felix, G., Duran, J.D., Volko, S., and Boller, T. 1999. Plants have a sensitive perception system for the most conserved domain of bacterial flagellin. Plant J.18:265-76.

Fu, Z. Q., and Dong, X. 2013. Systemic acquired resistance: Turning local infection into global defense. Annu. Rev. Plant Biol. 64:839-863.

Gaffney, T., Friedrich, L., Vernooij, B., Negrotto, D., Nye, G., Uknes, S., Ward, E., Kessmann, H., and Ryals, J. 1993. Requirement of salicylic Acid for the induction of systemic acquired resistance. Science 261:754-756.

Geethanandan, K., Abhilash, J., Bharath, S. R., Sadasivan, C., and Haridas, M. 2011. X-ray structure of a galactose-specific lectin from Spatholobous parviflorous. Int. J. Biol. Macromol. 49:992-998.

Heazlewood, J. L., Verboom, R. E., Tonti-Filippini, J., Small, I., and Millar A. H. 2007. SUBA: The Arabidopsis subcellular database. Nucleic Acids Res. 35:D213-218.

Hofius, D., Schultz-Larsen, T., Joensen, J., Tsitsigiannis, D. I., Petersen, N. H., Mattsson, O., Jorgensen, L. B., Jones, J. D., Mundy, J., and Petersen, M. 2009. Autophagic components contribute to hypersensitive cell death in Arabidopsis. Cell 137:773-783.

Hruz, T., Laule, O., Szabo, G., Wessendorp, F., Bleuler, S., Oertle, L., Widmayer, P., Gruissem, W., and Zimmermann, P. 2008. Genevestigator v3: A reference expression database for the meta-analysis of transcriptomes. Adv. Bioinf. 2008:420747.

Jiang, S. Y., Ma, Z., and Ramachandran, S. 2010. Evolutionary history and stress regulation of the lectin superfamily in higher plants. BMC Evol. Biol. 10:79.

Jones, J. D., and Dangl, J. L. 2006. The plant immune system. Nature 444:323-329

Liu, J., Elmore, J. M., Fuglsang, A. T., Palmgren, M. G., Staskawicz, B. J., and Coaker, G. 2009. RIN4 functions with plasma membrane H+ATPases to regulate stomatal apertures during pathogen attack. PLoS Biol. 7:e1000139.

Liu, J., Elmore, J. M., Lin, Z. J., and Coaker, G. 2011. A receptor-like cytoplasmic kinase phosphorylates the host target RIN4, leading to the activation of a plant innate immune receptor. Cell Host Microbe 9:137-146.

Livak, K. J., and Schmittgen, T. D. 2001. Analysis of relative gene expression data using real-time quantitative PCR and the 2 (-delta delta $\mathrm{C}(\mathrm{T})$ ) method. Methods 25:402-408.

Loake, G., and Grant, M. 2007. Salicylic acid in plant defence--the players and protagonists. Curr. Opin. Plant Biol. 10:466-472.

Lyou, S. H., Park, H. J., Jung, C., Sohn, H. B., Lee, G., Kim, C. H., Kim, M., Choi, Y. D., and Cheong, J. J. 2009. The Arabidopsis AtLEC gene encoding a lectin-like protein is up-regulated by multiple stimuli including developmental signal, wounding, jasmonate, ethylene, and chitin elicitor. Mol Cells 27:75-81.

Mackey, D., Holt, B. F., 3rd, Wiig, A., and Dangl, J. L. 2002. RIN4 interacts with Pseudomonas syringae type III effector molecules and is required for RPM1-mediated resistance in Arabidopsis. Cell 108:743754.

Mackey, D., Belkhadir, Y., Alonso, J. M., Ecker, J. R., and Dangl, J. L. 2003. Arabidopsis RIN4 is a target of the type III virulence effector AvrRpt 2 and modulates RPS2-mediated resistance. Cell 112:379-389.

Malinovsky, F. G., Brodersen, P., Fiil, B. K., McKinney, L. V., Thorgrimsen, S., Beck, M., Nielsen, H. B., Pietra, S., Zipfel, C., Robatzek, S.
Petersen, M., Hofius, D., and Mundy, J. 2010. Lazarus1, a DUF300 protein, contributes to programmed cell death associated with Arabidopsis acd11 and the hypersensitive response. PLoS One 5:e12586.

Monaghan, J., and Zipfel, C. 2012. Plant pattern recognition receptor complexes at the plasma membrane. Curr. Opin. Plant Biol. 15:349-357.

Morgenstern, B. 1999. DIALIGN 2: Improvement of the segment-to-segment approach to multiple sequence alignment. Bioinformatics 15:211218.

Nawrath, C., and Metraux, J. P. 1999. Salicylic acid induction-deficient mutants of Arabidopsis express PR-2 and PR-5 and accumulate high levels of camalexin after pathogen inoculation. Plant Cell 11:13931404

Nishimura, M. T., and Dangl, J. L. 2010. Arabidopsis and the plant immune system. Plant J. 61:1053-1066.

Notredame, C., Higgins, D. G., and Heringa, J. 2000. T-Coffee: A novel method for fast and accurate multiple sequence alignment. J. Mol. Biol. 302:205-217

Pavet, V., Olmos, E., Kiddle, G., Mowla, S., Kumar, S., Antoniw, J., Alvarez, M. E., and Foyer, C. H. 2005. Ascorbic acid deficiency activates cell death and disease resistance responses in Arabidopsis. Plant Physiol. 139:1291-1303.

Peumans, W. J., and Van Damme, E. J. 1995. Lectins as plant defense proteins. Plant Physiol. 109:347-352.

Pieterse, C. M., Leon-Reyes, A., Van der Ent, S., and Van Wees, S. C. 2009. Networking by small-molecule hormones in plant immunity. Nat. Chem. Biol. 5:308-316.

Ramonell, K., Berrocal-Lobo, M., Koh, S., Wan, J., Edwards, H., Stacey, G., and Somerville, S. 2005. Loss-of-function mutations in chitin responsive genes show increased susceptibility to the powdery mildew pathogen Erysiphe cichoracearum. Plant Physiol. 138:1027-1036.

Riou, C., Hervé, C., Pacquit, V., Dabos, P., and Lescure, B. 2002. Expression of an Arabidopsis lectin kinase receptor gene, lecRK-a1, is induced during senescence, wounding and in response to oligogalacturonic acids. Plant Physiol. Biochem. 40:431-438.

Sedbrook, J. C., Carroll, K. L., Hung, K. F., Masson, P. H., and Somerville, C. R. 2002. The Arabidopsis SKU5 gene encodes an extracellular glycosyl phosphatidylinositol-anchored glycoprotein involved in directional root growth. Plant Cell 14:1635-1648.

Sharon, N., and Lis, H. 2002. How proteins bind carbohydrates: Lessons from legume lectins. J. Agric. Food Chem. 50:6586-6591.

Sigrist, C. J., Cerutti, L., de Castro, E., Langendijk-Genevaux, P. S., Bulliard, V., Bairoch, A., and Hulo, N. 2010. PROSITE, a protein domain database for functional characterization and annotation. Nucleic Acids Res. 38:D161-166.

Singh, P., Kuo, Y. C., Mishra, S., Tsai, C. H., Chien, C. C., Chen, C. W. Desclos-Theveniau, M., Chu, P. W., Schulze, B., Chinchilla, D., Boller, T., and Zimmerli, L. 2012. The lectin receptor kinase-VI.2 is required for priming and positively regulates Arabidopsis pattern-triggered immunity. Plant Cell 24:1256-1270.

Strasser, R., Stadlmann, J., Svoboda, B., Altmann, F., Glossl, J., and Mach, L. 2005. Molecular basis of N-acetylglucosaminyltransferase I deficiency in Arabidopsis thaliana plants lacking complex N-glycans. Biochem. J. 387:385-391.

Summermatter, K., Sticher, L., and Metraux, J. P. 1995. Systemic responses in Arabidopsis thaliana infected and challenged with Pseudomonas syringae pv. syringae. Plant Physiol. 108:1379-1385.

Takemoto, D., and Jones, D. A. 2005. Membrane release and destabilization of Arabidopsis RIN4 following cleavage by Pseudomonas syringae AvrRpt2. Mol. Plant-Microbe Interact. 18:1258-1268.

Tamura, K., Peterson, D., Peterson, N., Stecher, G., Nei, M., and Kumar, S. 2011. MEGA5: Molecular evolutionary genetics analysis using maximum likelihood, evolutionary distance, and maximum parsimony methods. Mol. Biol. Evol. 28:2731-2739.

Tian, Y., Zhou, Y., Elliott, S., Aebersold, R., and Zhang, H. 2007. Solid phase extraction of N-linked glycopeptides. Nat. Protocols 2:334-339.

Truernit, E., and Haseloff, J. 2008. A simple way to identify non-viable cells within living plant tissue using confocal microscopy. Plant Methods $4: 15$.

Van Damme, E. J., Lannoo, N., and Peumans, W. J. 2008. Plant lectins Adv. Bot. Res. 48 107-209.

Vandenborre, G., Smagghe, G., and Van Damme, E. J. 2011. Plant lectins as defense proteins against phytophagous insects. Phytochemistry 72:1538-1550.

van Doorn, W. G., Beers, E. P., Dangl, J. L., Franklin-Tong, V. E., Gallois, P., Hara-Nishimura, I., Jones, A. M., Kawai-Yamada, M., Lam, E., Mundy, J., Mur, L. A., Petersen, M., Smertenko, A., Taliansky, M., Van Breusegem, F., Wolpert, T., Woltering, E., Zhivotovsky, B., and Bozhkov, P. V. 2011. Morphological classification of plant cell deaths. Cell Death Differ. 18:1241-1246.

Varet, A., Hause, B., Hause, G., Scheel, D., and Lee, J. 2003. The Arabi- 
dopsis NHL3 gene encodes a plasma membrane protein and its overexpression correlates with increased resistance to Pseudomonas syringae pv. tomato DC3000. Plant Physiol. 132:2023-2033.

Varki, A., Cummings, R. D., Esko, J. D., Freeze, H. H., Stanley, P. Bertozzi, C. R., Hart, G. W., and Etzler, M. E., eds. 2009. Essentials of Glycobiology, 2nd ed. Cold Spring Harbor Laboratory Press, Cold Spring Harbor, NY, U.S.A.

Vlot, A. C., Dempsey, D. A., and Klessig, D. F. 2009. Salicylic Acid, a multifaceted hormone to combat disease. Annu. Rev. Phytopathol. 47:177-206.

von Schaewen, A., Sturm, A., O’Neill, J., and Chrispeels, M. J. 1993. Isolation of a mutant Arabidopsis plant that lacks N-acetyl glucosaminyl transferase I and is unable to synthesize Golgi-modified complex Nlinked glycans. Plant Physiol. 102:1109-1118.

Wang, L., and Coppel, R. L. 2002. Triton X-114 phase partitioning for antigen characterization. Methods Mol. Med. 72:581-585.

Ward, E. R., Uknes, S. J., Williams, S. C., Dincher, S. S., Wiederhold, D. L., Alexander, D. C., Ahl-Goy, P., Metraux, J. P., and Ryals, J. A. 1991. Coordinate gene activity in response to agents that induce systemic acquired resistance. Plant Cell 3:1085-1094.

Wildermuth, M. C., Dewdney, J., Wu, G., and Ausubel, F. M. 2001. Isochorismate synthase is required to synthesize salicylic acid for plant defence. Nature 414:562-565.

Xiang, Y., Song, M., Wei, Z., Tong, J., Zhang, L., Xiao, L., Ma, Z., and
Wang, Y. 2011. A jacalin-related lectin-like gene in wheat is a component of the plant defence system. J. Exp. Bot. 62:5471-5483.

AUTHOR-RECOMMENDED INTERNET RESOURCES

The Arabidopsis Information Resource (TAIR) database: www.arabidopsis.org

Aramemnon plant membrane protein database: aramemnon.botanik.uni-koeln.de

big-PI Predictor, GPI Modification Site Prediction server: mendel.imp.ac.at/gpi/gpi_server.html

InterPro protein sequence analysis and classification database: www.ebi.ac.uk/interpro

National Center for Biotechnology Information BLAST database: blast.ncbi.nlm.nih.gov/Blast.cgi

NMT-The MYR Predictor server: mendel.imp.ac.at/myristate/SUPLpredictor.htm

PlantsP Plant-Specific Myristoylation Predictor server: plantsp.genomics.purdue.edu/myrist.html

Protein Data Bank (PDB) database: www.pdb.org/pdb/home/home.do

SIGnAL Salk Institute Genomic Analysis Laboratory database: www.signal.salk.edu

VIB Ghent University, Gateway vectors database: gateway.psb.ugent.be 